\title{
Sustentabilidade e desenvolvimento em uma área de fronteira: uma aplicação do Barômetro da Sustentabilidade no Oeste do Paraná
}

Flavia Hachmann

Departamento de Ciências Contábeis da Faculdade Luterana Rui Barbosa (Falurb)

Ricardo Rippel

Programa de Pós-Graduação em Desenvolvimento Regional e Agronegócio da Universidade Estadual do Oeste do Paraná (Unioeste/Campus Toledo)

Recebido: 14/05/2015 Versão revisada (entregue): 17/06/2015 Aprovado: 20/07/2015

\begin{abstract}
Resumo
Em virtude dos efeitos degradantes ao meio ambiente, decorrentes do crescimento econômico e do elevado padrão de consumo, fomentaram-se discussões acerca do Desenvolvimento Sustentável nas últimas décadas pela sociedade, como forma de garantir a qualidade de vida desta e das futuras gerações através da gestão adequada dos recursos naturais. Assim sendo, a pesquisa teve como objetivo geral analisar o Desenvolvimento Sustentável da Mesorregião Oeste do Paraná, em comparação com o restante deste Estado, para os anos de 2000 e 2010, avaliando o Bem-Estar do Sistema Humano e o Bem-Estar do Sistema Ambiental da região, através de um levantamento de dados e a utilização da ferramenta Barômetro da Sustentabilidade. O método de pesquisa utilizado foi o quantitativo-qualitativo, na medida em que foram empregadas técnicas para análise, decomposição, agregação e discussão dos dados. Além disso, em seus aspectos metodológicos, a pesquisa tem característica exploratória e documental. Os resultados demonstraram que a Mesorregião Oeste do Paraná classificou-se, no ano de 2000, como Quase Insustentável, e, em 2010, como Insustentável.
\end{abstract}

Palavras-chave | Barômetro da Sustentabilidade; Desenvolvimento sustentável; meio ambiente; Paraná.

Código JEL | O18; Q01; Q56. 


\title{
SUSTAINABILITY AND DEVELOPMENT IN A BOUNDARY AREA: AN APPLICATION OF THE SUSTAINABILITY BAROMETER IN WESTERN PARANÁ
}

\begin{abstract}
Due to the degrading effects to the environment, resulting from the economic growth and from the high consumption standards, discussions about Sustainable Development have been widely discussed in recent decades by mankind in order to ensure the quality of life of the present and future generations through proper management of natural resources. Therefore, the research aimed to analyze the Sustainable Development of West of Paraná region (Brazil) in comparison with the rest of the state, for the years 2000 and 2010, evaluating the Human System Welfare, as well the Welfare of the Regional Environmental System, through a data collection and the use of Barometer of Sustainability tool. The research method was quantitative and qualitative, to the extent that techniques for analysis, decomposition, aggregation and discussion of data were employed. Moreover, in its methodological aspects, the research has an exploratory and documentary feature. The results showed that the West of Paraná region ranked in 2000 as Nearly Untenable and in 2010 as Untenable.
\end{abstract}

Keywords | Barometer of Sustainability; environment; State of Paraná; sustainable development.

JEL-Code | O18; Q01; Q56.

\section{SOSTENIBILIDAD Y DESARROLLO EN UNA ZONA DE FRONTERA: UNA APLICACIÓN DEL BARÓMETRO DE LA SOSTENIBILIDAD EN EL OESTE DE PARANÁ}

\section{Resumen}

Debido a los efectos degradantes para el medio ambiente, resultantes del crecimiento económico y de los altos estándares de consumo, las discusiones sobre el Desarrollo Sostenible han sido ampliamente discutido en las últimas décadas por la humanidad a fin de garantizar la calidad de vida de las generaciones presentes y futuras a través de la gestión adecuada de los recursos naturales. Por lo tanto, la investigación tuvo como objetivo analizar el desarrollo sostenible de mesoregión Oeste de Paraná (Brasil), en comparación con el resto del Estado, para los años 2000 y 2010, la evaluación del bienestar del sistema humano y el bienestar del sistema ambiental de la región, a través de la recopilación de datos y el uso del Barómetro de la herramienta de Sostenibilidad. El método de investigación fue cuantitativa y cualitativa, en la medida en que se emplearon técnicas para el análisis, descomposición, agregación y análisis de datos. Además, en sus aspectos metodológicos, la investigación tiene una función exploratoria y documental. Los resultados mostraron que la mesoregión Oeste de Paraná clasificado en 2000 como casi insostenible y en 2010 como insostenible.

Palabras-clave | Barómetro de la Sostenibilidad; desarrollo sostenible; Estado de Paraná; medio ambiente.

Código JEL | O18; Q01; Q56. 


\section{Introdução}

As questões relativas ao Desenvolvimento Sustentável vêm sendo amplamente discutidas, nas últimas décadas, por grande parte da humanidade, como forma de garantir a qualidade de vida desta e das futuras gerações, fundamentalmente pela gestão adequada dos recursos naturais. De acordo com Buarque (1994), o desenvolvimento sustentável gera um processo de mudança social e elevação das oportunidades, promovendo o crescimento e a eficiência econômicos, a conservação ambiental, a qualidade de vida e a equidade social, partindo de um claro compromisso com o futuro e da solidariedade entre gerações.

Desta maneira, buscar alternativas para a gestão adequada dos recursos naturais e a criação de condições que propiciem a sustentabilidade da população são de vital importância na redução da degradação ambiental, assim rejeitam-se os modelos de exploração destrutiva dos recursos naturais praticados até hoje, e se busca sua proteção em benefício desta e das gerações vindouras. Deste modo, o desenvolvimento sustentável pode ser entendido como o grau de evolução de uma dada sociedade ou território que considera não somente a dimensão econômica, mas também a dimensão ambiental e a dimensão social. Assim sendo, um novo desafio é colocado perante a sociedade, o de como incorporar a dinâmica ambiental no centro da discussão do desenvolvimento.

Neste texto busca-se analisar o Desenvolvimento Sustentável da Mesorregião Oeste do Paraná, a última área desta UF a ser ocupada, que compreende atualmente 50 municípios e é a terceira região em valor agregado bruto no Estado (IPARDES, 2014). Segundo Rippel (2005), o processo de apropriação territorial e expansão da fronteira agrícola da região ocorreu em curto espaço de tempo, no período que compreende as décadas de 1940 à 1970, quando a área possuía uma população estimada em 7.645 habitantes em 1940, que cresce para $768.271 \mathrm{em}$ 1970. Mantendo o seu ritmo de crescimento a área continuou a expandir seu montante de população, atingindo, segundo o IBGE, um total de 1.219.558 habitantes em 2010, e alcançando o total de 1.286.612 habitantes em 2014 (IPARDES, 2014).

Ainda segundo Rippel (2013), a acelerada transformação demográfica da região propiciou o surgimento de intensos fluxos migratórios na área, impactando diretamente no seu meio ambiente, tanto que Bonchristiani, Kuhn e Shikida (2005) apontam que o rápido crescimento, seguido da agricultura intensiva evidente no local, a partir da colonização da Mesorregião Oeste do Paraná (cuja localização pode ser vista no mapa a seguir), contribuiu para a ocorrência de diversos problemas de impactos ambientais, principalmente sobre os solos e as águas. 
Figura 1 Mesorregião Oeste do Paraná

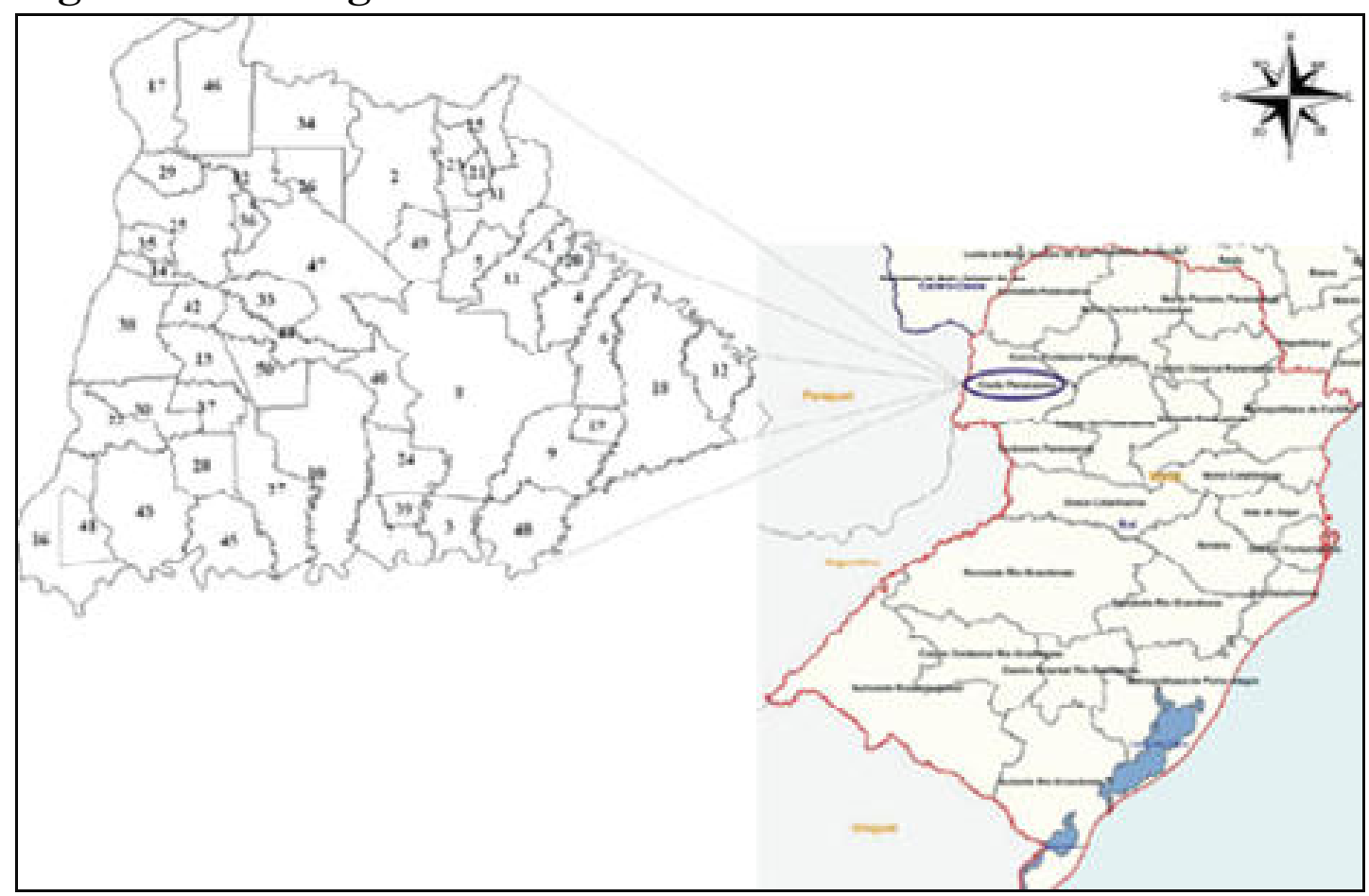

Fonte: IBGE, 2012.

Por este motivo, evidencia-se o interesse dessa pesquisa pela Mesorregião Oeste do Estado do Paraná, onde se buscou aprofundar o conhecimento sobre as relações da sociedade com o meio ambiente, avaliando o Desenvolvimento Sustentável da área. Portanto, chegou-se ao seguinte problema de pesquisa: Em que estágio do Desenvolvimento Sustentável, encontra-se a Mesorregião Oeste do Estado do Paraná em relação ao restante do Estado, para os anos de 2000 e 2010, e se houve alguma evolução nesse periodo?

\section{Desenvolvimento sustentável}

A partir do ano de 1972, ocorreram intensas discussões em todo o mundo, tanto em meios científicos, como nas empresas e na sociedade em geral, sobre os rumos do crescimento econômico e os caminhos para desenvolvimento dos países, incluindo a preocupação com o meio ambiente. Todas essas discussões culminaram com a Conferência das Nações Unidas sobre o Meio Ambiente Humano, em Estocolmo, capital da Suécia, e a publicação do primeiro relatório denominado "Limites ao Crescimento" (The Limits to Growth) (HOGAN, 2007). Dessa forma, o ano de 1972 se tornou um marco para a questão ambiental, pois foi a primeira vez que representantes dos países industrializados e em 
desenvolvimento reuniram-se para discutir a questão do meio ambiente global e do desenvolvimento do planeta.

Na sequência, em 1974, aconteceu em Cocoyoc, no México, a Conferência das Nações Unidas sobre Comércio e Desenvolvimento; oito anos depois, em 1982, realizou-se em Nairóbi, capital do Quênia, mais um encontro, que resultou na formação da Comissão Mundial de Meio Ambiente e Desenvolvimento. Em 1987, essa comissão publicou o relatório "Nosso Futuro Comum", no qual, pela primeira vez, foi utilizado o conceito de Desenvolvimento Sustentável, então definido como "desenvolvimento que atende às necessidades das gerações atuais sem comprometer a capacidade de as futuras gerações terem suas próprias necessidades atendidas.” (HOGAN, 2007, p. 63).

Em 1992, contando com a participação de 178 líderes mundiais, ocorreu no Rio de Janeiro a Conferência das Nações Unidas sobre Meio Ambiente e Desenvolvimento, que ficou conhecida como Cúpula da Terra "Eco 92" ou Rio92. Nesse encontro, foi produzida uma série de documentos que sintetizavam os anseios do planeta, relacionando temas como desigualdade entre pobres e ricos, padrões de produção e consumo e combate à degradação ambiental. Dentre os principais documentos, um de maior importância para esta discussão foi a Agenda 21 (MELLO, 2003).

Já em 1997 aconteceu no Cairo a Sessão Especial da Assembleia Geral das Nações Unidas, conhecida como Rio+5; no ano de 2002 ocorreu em Joanesburgo, na África do Sul, a Rio+10; e mais recentemente, em 2012, ocorreu a Rio+20, novamente no Rio de Janeiro, vinte anos após a Conferência das Nações Unidas sobre Meio Ambiente e Desenvolvimento (Eco-92). Ao longo dos vinte anos que separam as duas conferências mundiais sobre o meio ambiente, consolidou-se a consciência de que simplesmente não é possível, do ponto de vista ecológico, a generalização em escala mundial dos padrões tecnológicos de produção e de consumo prevalecentes nas atuais economias industriais. A questão ambiental tornou-se ponto obrigatório de qualquer agenda de políticas públicas (ROMEIRO; REYDON; LEONARDI, 1999).

Conforme o exposto, o desenvolvimento sustentável centra sua atenção na relação dos homens com a natureza, preconizando a utilização racionalizada dos estoques de recursos naturais, assim a preocupação está voltada às gerações futuras e à necessidade de políticas que preconizem um desenvolvimento harmonioso e, prioritariamente, sustentável nos períodos posteriores. Leal e Peixe (2010) argumentam que o conceito de sustentabilidade é o de "que se pode sustentar". Esse conceito relaciona-se com as atitudes que permitem relações de continuidade, de proteção e de resistência perante determinada circunstância. Além disso, em relação ao meio ambiente, e nele incluindo o ser humano, a sustentabilidade apoiase nas ações que permitam continuidade dos seres vivos em sua totalidade, ou seja, em sua forma atual e na possibilidade de evolução natural. 
Woehl (2008), estudando a questão, afirmou que a economia deve ser voltada para o desenvolvimento sustentável e o bem-estar comum, ou seja, deve-se acabar com a miséria, promover a justiça e a dignidade para todos, deve-se construir instrumentos de avaliação e a concretização de atitudes, canalizando racionalmente os esforços produtivos para resultados sustentáveis, ocorrendo uma mudança de enfoque, em que o bem-estar passa a ser objeto e a economia volta a ser o meio.

Outro autor a tratar da questão é Boff (2012), o qual sustenta que em virtude da crescente degradação da natureza e suas consequências sobre a vida humana, há uma pressão mundial sobre os governos e sobre as empresas no sentido de juntar esforços para conferir sustentabilidade ao desenvolvimento. Assim, a primeira tarefa foi o início das reduções de emissões de dióxido de carbono e outros gases que geram o efeito estufa, e a tomada de consciência dos termos reduzir, rentilizar e reciclar os materiais, como também redistribuir benefícios, rejeitar o consumismo, respeitar todos os seres e reflorestar.

Para auxiliar o monitoramento da eficiência das políticas adotadas para atingir o desenvolvimento sustentável, Oliveira (2002) sustenta que é necessária a mensuração do desenvolvimento a partir de Indicadores de Desenvolvimento Sustentável que apontem essencialmente a qualidade de vida e o desenvolvimento humano da população.

\section{Indicadores de Desenvolvimento Sustentável}

Quando se fala em conscientização, em preservar os finitos recursos naturais, diminuir a emissão de poluentes, a busca pela igualdade social e a busca pelo crescimento econômico sem a degradação do meio ambiente, faz-se necessária a mensuração do desenvolvimento sustentável, ou seja, torna-se indispensável um acompanhamento que possibilite a sua percepção a curto, médio e longo prazo, seja em nível local, regional ou mundial.

Conforme apontado pela Agenda 21, os países devem desenvolver sistemas de monitoramento e de avaliação do avanço para o desenvolvimento sustentável, adotando indicadores que mensurem as mudanças nas dimensões econômica, social e ambiental (AGENDA 21, 1992).

Segundo o IBGE (2012), os Indicadores do Desenvolvimento Sustentável medem a qualidade ambiental, a qualidade de vida da população, o desempenho econômico e a governança para o desenvolvimento sustentável, nos temas biodiversidade, saneamento, água doce, saúde, educação, segurança, padrões de produção e consumo, capacidade institucional, entre outros aspectos. Em suma, os indicadores permitem acompanhar a sustentabilidade, do padrão de desenvolvimento, nas dimensões ambiental, social, econômica e institucional, 
fornecendo um panorama abrangente de informações para subsidiar decisões em políticas para o desenvolvimento sustentável.

Os indicadores são, portanto, utilizados para monitorar sistemas complexos considerados importantes, pois contém informações que apontam as características ou o que está ocorrendo com o sistema, podendo ser uma variável ou uma função de variáveis. Conforme Siena (2002), os indicadores sintetizam a informação que tem valor para o observador e ajudam a construir um quadro do estado do ambiente. Neste contexto, a variabilidade dos modelos de indicadores permite a escolha do mais adequado a sua temática e oferece a possibilidade de adaptações de acordo com a realidade local pesquisada. Então os indicadores de desenvolvimento sustentável tornam-se importantes para as etapas de análise e parecer da questão, atuando como ferramentas de visão de conjunto bem como na maior integração dos componentes da sustentabilidade, criando condições adequadas de acompanhamento pelas partes interessadas e a consequente tomada de decisão.

Outro autor a tratar da questão, Krama (2009), argumenta que para atender a necessidade de medir e avaliar o desenvolvimento sustentável construíram-se vários modelos de indicadores, sendo que a maioria objetivou apontar os problemas e impactos causados pelo crescimento econômico sobre o meio ambiente, caso do Pressure-State-Response (Pressão-Estado-Resposta) e o IDH (Índice de Desenvolvimento Humano). Com estas importantes transformações na interpretação do cenário na maioria dos países, a partir dos indicadores citados, passou a existir uma pressão para o surgimento de indicadores que retratassem também a realidade social e institucional de cada nação e território.

Como consequência, diversos modelos de análise da questão vêm sendo construídos e testados por vários grupos de pesquisadores, sendo os mais conhecidos: A Pegada Ecológica (Ecological Footprint), desenvolvido por Wackernagel e Rees em 1996; o Barômetro da Sustentabilidade (Barometer of Sustainability), desenvolvido em 1997 pelo The Word Conservation Unit e The International Development Research Centre; e o modelo Painel de Sustentabilidade (Dashboard of Sustainability), desenvolvido em 1999 pelo International Institute for Sustainable Development. Dentre estes, utilizou-se o Barômetro da Sustentabilidade para a análise do Oeste do Paraná.

\section{Barômetro da Sustentabilidade}

Desenvolvida por especialistas ligados aos institutos International Union for Conservation of Nature (IUCN) e The International Development Research Centre (IDRC), entre eles Prescott-Allen, a ferramenta Barômetro da Sustentabilidade, ou Barometer of Sustainability, corresponde a uma metodologia que 
avalia e relata o progresso em direção a sociedades sustentáveis, combinando, de modo coerente, diversos indicadores sociais e ambientais, tendo por resultado uma avaliação do estado das pessoas e do meio ambiente, por meio de uma escala de índices, e sendo adotado como método oficial de avaliação da sustentabilidade do IUNC (LOUETTE, 2009).

Isto ocorreu porque ao analisar modelos de medição da sustentabilidade da década de 90, Prescott-Allen percebeu que a maior parte dos indicadores utilizava como unidade comum a monetarização, entretanto, essa medida se propõe apenas a avaliar comércio e mercado, fato que segundo ele a tornava frágil, uma vez que muitos aspectos relativos à sustentabilidade não têm preço no mercado, logo, tornou-se necessária a utilização de uma escala de desempenho, possibilitando a combinação de diferentes dimensões com menor risco de distorção, e assim chegar ao produto final da medição (PRESTES, 2010).

Assim o Barômetro da Sustentabilidade constitui-se num instrumento de avaliação que faz uso de indicadores conectados ao bem-estar humano e ao bem-estar do meio ambiente, sendo que cada uma das dimensões decompõe-se em outras cinco: i) para o bem-estar do meio ambiente, a terra, o ar, a água, as espécies e utilização de recursos; e ii) para o bem-estar humano: saúde e população (saúde), riqueza (econômica), conhecimento e cultura (educação), comunidade e equidade (LUCENA; CAVALCANTE; CÂNDIDO; 2011).

Figura 2 Dimensões dos Sistemas Humano e Ambiental
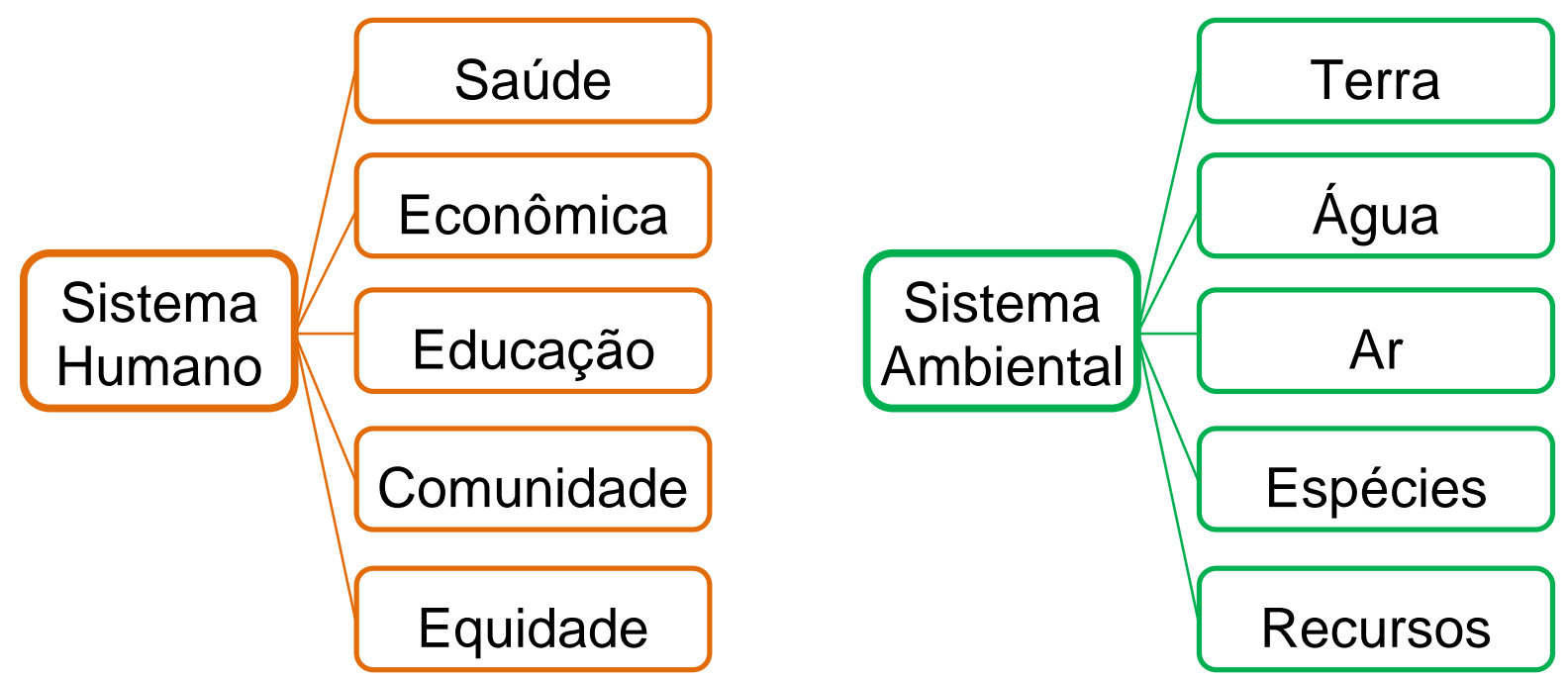

Fonte: Adaptado de Prestes (2010).

Segundo Prescott-Allen (2001), essa metodologia de avaliação permite que o usuário escolha as suas próprias dimensões, de acordo com a realidade e conhecimento sobre o local estudado, devendo-se trabalhar com no mínimo três e no máximo cinco dimensões para cada sistema, humano e ambiental. Tanto que 
Siena (2002) sustenta que uma das principais características do Barômetro da Sustentabilidade, e vantagem perante outros indicadores, é sua capacidade de combinar indicadores, permitindo ao usuário chegar a uma conclusão a partir de muitos dados considerados na pesquisa. Essa característica é relevante frente à grande variedade de questões e dimensões encontradas ao avaliar o estado das pessoas e do meio ambiente em busca do desenvolvimento sustentável. Diante dessa perspectiva, na Figura 3 encontra-se ilustrada a estrutura do Barômetro da Sustentabilidade e seus respectivos eixos relativos ao bem-estar do Sistema Humano e bem-estar do Sistema Ambiental, onde indicadores socioeconômicos e ambientais são combinados.

\section{Figura 3 Barômetro da Sustentabilidade}

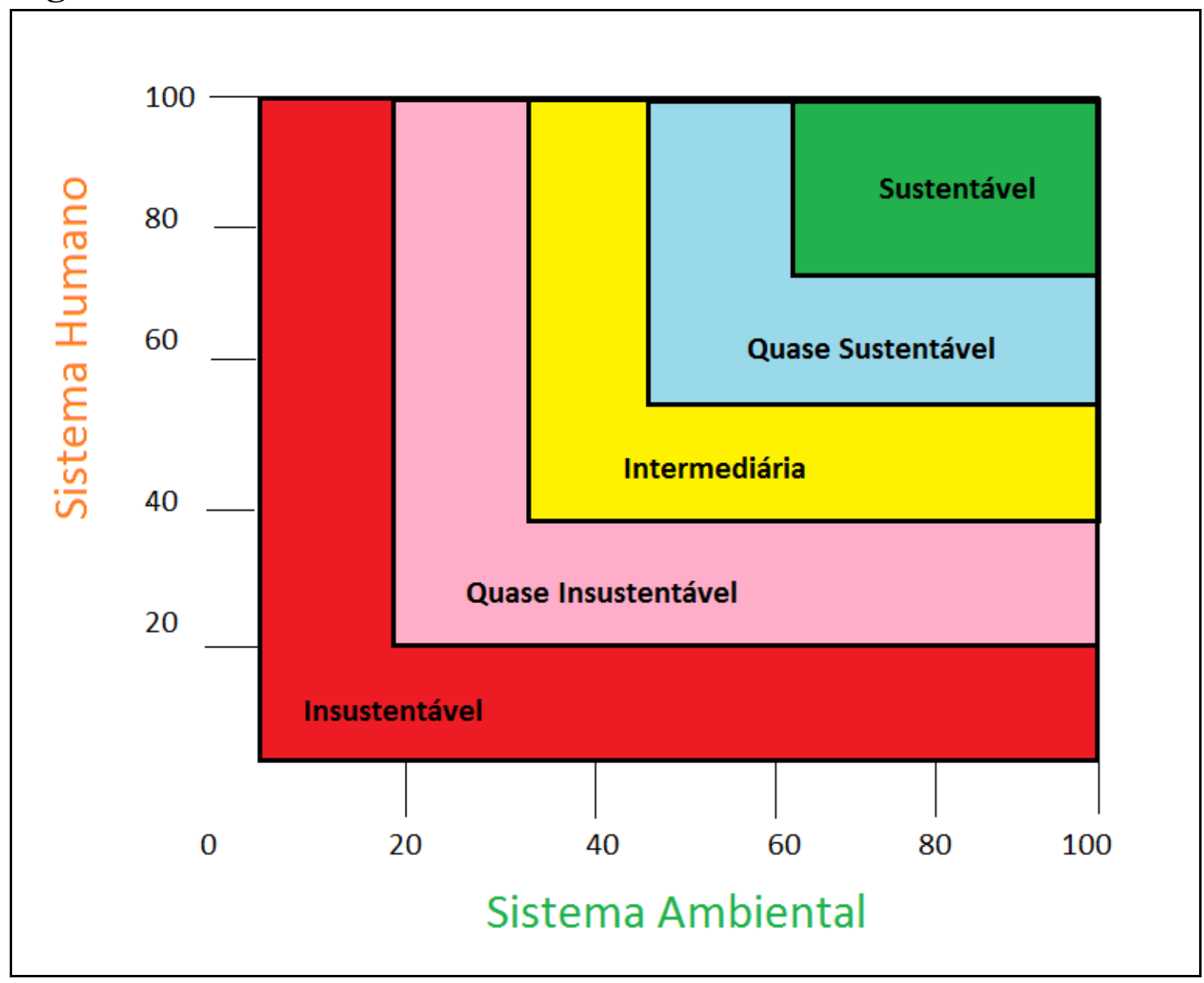

Fonte: Siena (2002, p. 54).

Outro autor que investiga a questão, Van Bellen (2002) acrescenta que para medir o progresso em direção ao desenvolvimento sustentável, no Barômetro da Sustentabilidade, os valores para os índices de bem-estar social são calculados formando um gráfico bidimensional e são alocados em escalas relativas que vão de 0 a 100, indicando uma situação de ruim até bom em relação à sustentabilidade. 
De modo que a localização do sistema estudado dentro desse gráfico fornece uma medida de sustentabilidade ou insustentabilidade do sistema. Segundo Lucena, Cavalcante e Cândido (2011), o Barômetro da Sustentabilidade não encontra limites no que se refere a sua aplicação, podendo ser utilizado para análise tanto numa escala local quanto numa escala global.

Pode-se, assim, observar que o Barômetro da Sustentabilidade constitui uma ferramenta de avaliação das condições humanas e ambientais e do progresso em direção à sustentabilidade. Desse modo, considerando que a ferramenta possui facilidade no seu uso, clareza na apresentação dos resultados e, principalmente, confiabilidade frente a parâmetros de indicadores internacionalmente utilizados, o Barômetro da Sustentabilidade foi o modelo selecionado para a aplicação nessa pesquisa.

\section{Procedimentos metodológicos}

Em relação à abordagem do problema, a pesquisa tem característica quantitativaqualitativa. A abordagem quantitativa justifica-se na medida em que foram empregadas técnicas para análise, decomposição e agregação de dados, visando compor a ferramenta Barômetro da Sustentabilidade. Sendo que a perspectiva qualitativa justifica-se como sendo essencial para discussão de dados e informações, especialmente na escolha dos aspectos e indicadores a serem considerados para avaliação, na interpretação dos fenômenos e na atribuição de significados, permitindo a compreensão por meio de comentários aos resultados auferidos pela região em análise, referentes aos seus respectivos indicadores.

Assim sendo, a utilização de aproximações qualitativas e quantitativas em conjunto demonstra que a análise da pesquisa se torna mais efetiva, principalmente para os estudos de desenvolvimento sustentável, devido a sua característica multidisciplinar. Logo, entende-se como essencial a possibilidade de adotar tanto o método quantitativo, pela utilização de técnicas de decomposição e de agregação de dados, quanto o método qualitativo pela consideração do contexto da unidade em avaliação.

O estudo é documental, uma vez que foram utilizados dados secundários, coletados junto a órgãos oficiais de abrangência nacional, estadual e municipal, entre os quais, o Instituto Brasileiro de Geografia e Estatística (IBGE), o Instituto Paranaense de Desenvolvimento Econômico e Social (IPARDES), o Atlas do Desenvolvimento Humano, desenvolvido pelo Programa das Nações Unidas para o Desenvolvimento (PNUD), o Departamento de Informática do Sistema Único de Saúde (DATASUS), o Instituto Nacional de Pesquisas Espaciais (INPE), entre outros. 


\section{Coleta, análise e interpretação dos dados}

A coleta de dados desta pesquisa foi realizada no segundo semestre de 2014 e a população compreendeu a Mesorregião Oeste do Estado do Paraná, ou seja, um conjunto de 50 municípios expostos pela média regional. A partir do Sistema Humano, que abarca as Dimensões Saúde, Econômica, Educação, Comunidade e Equidade, foram pesquisados os seguintes indicadores: Taxa de Mortalidade Infantil, Esperança de Vida ao Nascer (anos), Casos HIV/AIDS (cada dez mil habitantes), Domicílios com Acesso à Rede de Esgoto ou Fossa Séptica (\%), Índice de Desenvolvimento Humano Municipal, Índice de Gini, Produto Interno Bruto per capita, Renda Média Domiciliar per capita, Taxa de Analfabetismo de 15 anos ou mais (\%), Instituições de Ensino Superior (cada dez mil habitantes), Percentual da população com 18 anos ou mais com Ensino Fundamental Completo, Expectativa de anos de estudo, Taxa de Óbitos por Causas Externas (cada cem mil habitantes), Razão de Sexo (\%), Mulheres Assalariadas no Emprego Formal (\%) e Taxa de Pobreza (\%).

Da mesma forma, a partir do Sistema Ambiental, em que foram analisadas as Dimensões Terra, Ar e Recursos, foram levantados os seguintes indicadores: Cobertura por Mata Atlântica Remanescente (\%), Razão de Veículos (mil habitantes), Despesas Municipais com Gestão Ambiental per capita (R\$) e Recebimento de ICMS Ecológico per capita (R\$). E para compor a Escala de Desempenho, necessária à padronização dos dados, foram levantados o maior e menor índice, referente a cada indicador, para o Estado do Paraná, ficando os resultados enquadrados em um intervalo de 0 à 100, chamado de Equivalência Centesimal, sendo considerados, portanto, quanto mais próximos a 100, mais sustentáveis.

Portanto, alguns indicadores seguiram a lógica direta, quanto maior o valor do indicador melhor o resultado, foi o caso dos indicadores Esperança de Vida ao Nascer, Domicílios Atendidos com Rede de Esgoto ou Fossa Séptica, Índice de Desenvolvimento Humano, Produto Interno Bruto, Renda Média Domiciliar per capita, Instituições de Ensino Superior, Percentual de 18 anos ou mais com Ensino Fundamental Completo, Expectativa de Anos de Estudo, Proporção de Mulheres Assalariadas no Emprego Formal, Cobertura por Mata Atlântica Remanescente, Despesas Municipais com Gestão Ambiental e Recebimento de ICMS Ecológico. E outros seguiram a lógica inversa, quanto menor o valor do indicador melhor o resultado, o que aconteceu com os indicadores Taxa de Mortalidade Infantil, Casos de HIV/AIDS, Índice de Gini, Taxa de Analfabetismo de 15 anos ou mais, Taxa de Óbitos por Causas Externas, Taxa de Pobreza e Razão de Veículos.

Para um indicador em especial, a metodologia do cálculo da Equivalência Centesimal ocorreu de forma semelhante - é o caso do indicador Razão de Sexo. Considerando que os dados obtidos oscilaram abaixo e acima do valor de 
referência (100), foram considerados melhores os resultados mais próximos a 100 (perfeita igualdade entre homens e mulheres). Desta forma, a partir da padronização dos indicadores foi possível agregá-los, formando médias aritméticas por dimensão e para a Mesorregião Oeste, configurando índices, um para o Sistema Humano, outro para o Sistema Ambiental, que, por sua vez, foram lançados nos dois eixos do Gráfico do Barômetro da Sustentabilidade, avaliando o bem-estar dos dois sistemas e possibilitando a análise da sustentabilidade da região.

\section{Análise do desenvolvimento sustentável da Mesorregião Oeste do Paraná}

A pesquisa fez uso de 16 (dezesseis) indicadores correspondentes ao Sistema Humano, e 4 (quatro) indicadores correspondentes ao Sistema Ambiental. O número menor de indicadores para o Sistema Ambiental representa a dificuldade encontrada em localizar informações, ao longo do período analisado (2000 e 2010), sobre os aspectos relacionados ao meio-ambiente, uma vez que a discussão sobre o tema Desenvolvimento Sustentável ainda é considerada recente.

Segundo a metodologia do Barômetro da Sustentabilidade, desenvolvido por Prescott-Allen (2001), a partir dos extremos (0-100), o intervalo entre eles foi dividido em cinco partes iguais, utilizando-se de interpolação simples para composição das Escalas de Desempenho, classificando-se, portanto, de 0 a 20 Insustentável; 20 a 40 - Quase Insustentável; 40 a 60 - Intermediária; 60 a 80 Quase Sustentável; e 80 a 100 - Sustentável. Na sequência foram elaboradas tabelas visando à ilustração dos parâmetros utilizados para cada Escala de Desempenho, conforme as Dimensões e seus indicadores:

\section{Tabela 1 Parâmetros da Escala de Desempenho dos Indicadores relacionados à Dimensão Saúde}

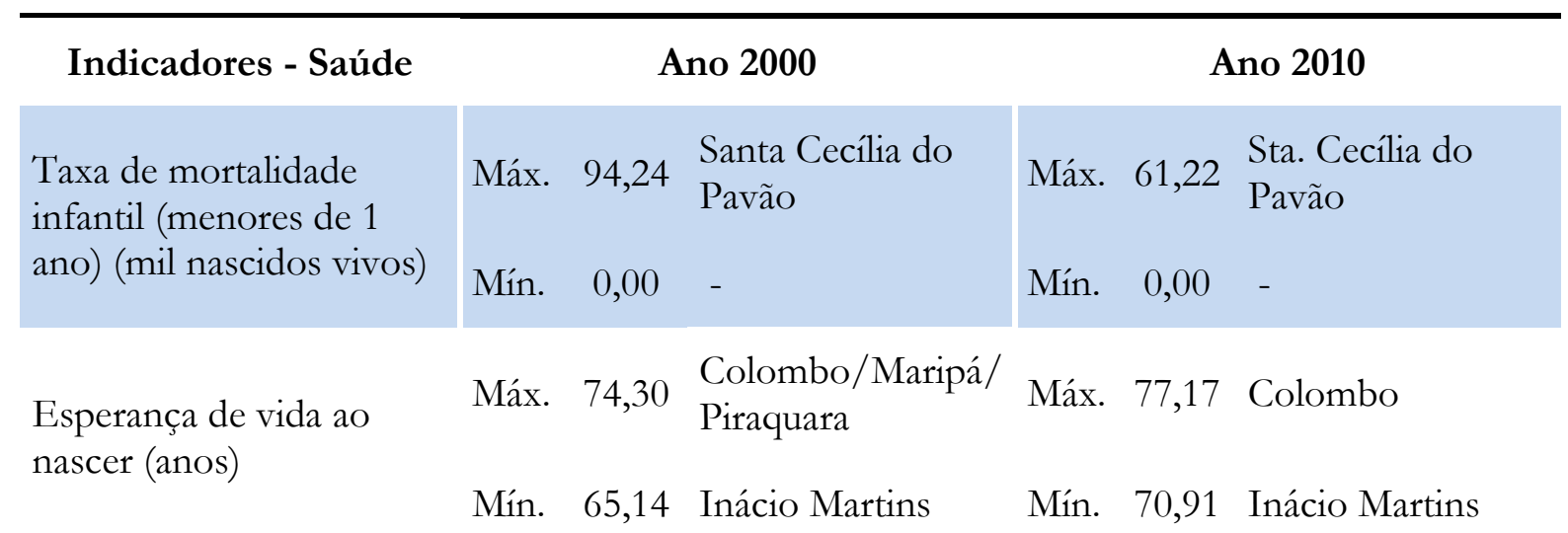




\begin{tabular}{l|lrl|lll}
$\begin{array}{l}\text { Número de casos por } \\
\text { HIV /AIDS (cada dez mil } \\
\text { habitantes) }\end{array}$ & Máx. $7,474 \begin{array}{l}\text { Nova Aliança do } \\
\text { Ivaí }\end{array}$ & Máx. 6,214 & Pontal do Paraná \\
& Mín. 0,00 & - & Mín. 0,00 & - \\
\hline $\begin{array}{l}\text { Domicílios (urbanos e } \\
\text { rurais) com acesso à rede } \\
\text { geral de esgoto ou fossa } \\
\text { séptica }(\%)\end{array}$ & Máx. & Mín. & $0,05,25$ & $\begin{array}{l}\text { Pontal do Paraná } \\
\text { Iguaçú }\end{array}$ & Máx. 94,27 Ibiporã \\
\hline
\end{tabular}

Fonte: Adaptado do Banco de Dados do Ipardes; Pnud (2014).

A maior Taxa de Mortalidade Infantil observada no Estado foi verificada no município de Santa Cecília do Pavão, com um índice de 94,24 óbitos para cada 1.000 crianças nascidas vivas para o ano de 2000 e 61,22 para o ano de 2010, apresentando uma queda acentuada de 35\% em uma década. Já a menor Taxa de Mortalidade Infantil do Estado apresentou índice zero para vários municípios. Segundo o Atlas do Desenvolvimento Humano desenvolvido pelo PNUD, a Esperança de Vida ao Nascer no Estado do Paraná aumentou, seguindo no topo da lista o município de Colombo, onde as crianças ali nascidas no ano de 2010 tiveram esperança de vida de mais de 77 anos.

Quanto ao número de pessoas infectadas pelo vírus HIV/AIDS houve uma queda de aproximadamente $17 \%$ no período, nas cidades que apresentaram os maiores índices, de acordo com os dados do IPARDES, o que pode estar relacionado a diversas causas: pessoas infectadas que entraram em óbito no período analisado e/ou diminuição das transmissões, ou ainda, os que se mudaram de cidade, dissipando-se os casos entre os municípios.

\section{Tabela 2 Parâmetros da Escala de Desempenho dos Indicadores relacionados à Dimensão Econômica}

\section{Indicadores - \\ Econômica}

\begin{tabular}{|c|c|c|c|c|c|c|}
\hline $\begin{array}{l}\text { Índice de } \\
\text { Desenvolvimento } \\
\text { Humano (IDH-M) }\end{array}$ & $\begin{array}{l}\text { Máx. } \\
\text { Mín. }\end{array}$ & $\begin{array}{l}0,75 \\
0,38\end{array}$ & $\begin{array}{l}\text { Curitiba } \\
\text { Doutor Ulysses }\end{array}$ & $\begin{array}{l}\text { Máx. } \\
\text { Mín. }\end{array}$ & 0,82 & $\begin{array}{l}\text { Curitiba } \\
\text { Doutor Ulysses }\end{array}$ \\
\hline \multirow{2}{*}{$\begin{array}{l}\text { Índice de Gini - } \\
\text { Geral }\end{array}$} & Máx. & 0,72 & Sengés & Máx. & 0,66 & Jardim Alegre \\
\hline & Mín. & 0,38 & N. S. das Graças & Mín. & 0,33 & $\begin{array}{l}\text { N.S. das Graças/ } \\
\text { Pitangueiras }\end{array}$ \\
\hline
\end{tabular}




\begin{tabular}{lllllll}
$\begin{array}{l}\text { Produto Interno } \\
\begin{array}{l}\text { Bruto per capita } \\
(\mathrm{R} \$ 1,00)\end{array}\end{array}$ & Máx. & $40.108,00$ & Araucária & Máx. & $103.777,70$ & Araucária \\
$\begin{array}{l}\text { Renda média } \\
\begin{array}{l}\text { domiciliar per capita } \\
(\mathrm{R} \$ 1,00)\end{array}\end{array}$ & Máx. & $2.394,00$ & Tunas do Paraná & Mín. & $5.869,16$ & Piraquara \\
\hline
\end{tabular}

Fonte: Adaptado do Banco de Dados do Ipardes; Banco de Dados do Ibge.

Para os indicadores de ordem Econômica, Curitiba foi o município do Estado do Paraná com o melhor desempenho no Índice de Desenvolvimento Humano Municipal para os dois períodos analisados, 2000 e 2010. Lembrando que este indicador representa quanto mais próximo a 1 melhor o Desenvolvimento Humano em determinada localidade. Com o pior desempenho referente ao IDH$\mathrm{M}$ e também referente à Renda Média Domiciliar per capita ficou o município de Doutor Ulysses, nos dois anos pesquisados.

Quanto ao Índice de Gini, o qual representa a concentração de renda da população, este apresentou um considerável decréscimo, em torno de 8 a 13\%, correspondente à taxa máxima e mínima respectivamente, representando uma melhor distribuição de renda no Estado do Paraná do ano de 2000 para 2010, de acordo com o IPARDES. Conforme o Instituto Brasileiro de Geografia e Estatística, o indicador Produto Interno Bruto apresentou o maior valor per capita no município de Araucária, região metropolitana de Curitiba, que ficou com a maior posição no Estado. Quanto à Renda Média Domiciliar per capita, novamente o município de Curitiba ficou com a maior classificação do Estado.

\section{Tabela 3 Parâmetro da Escala de Desempenho dos Indicadores relacionados à Dimensão Educação}

\begin{tabular}{|c|c|c|c|c|c|c|}
\hline $\begin{array}{c}\text { Indicadores - } \\
\text { Educação }\end{array}$ & & & 2000 & & & 2010 \\
\hline $\begin{array}{l}\text { Taxa de } \\
\text { Analfabetismo de } \\
15 \text { anos ou mais (\%) }\end{array}$ & $\begin{array}{l}\text { Máx. } \\
\text { Mín. }\end{array}$ & $\begin{array}{r}28,97 \\
2,43\end{array}$ & $\begin{array}{l}\text { Godoy Moreira } \\
\text { Quatro Pontes }\end{array}$ & $\begin{array}{l}\text { Máx. } \\
\text { Mín. }\end{array}$ & $\begin{array}{l}19,53 \\
1,24\end{array}$ & $\begin{array}{l}\text { Rosário do Ivaí } \\
\text { Quatro Pontes }\end{array}$ \\
\hline $\begin{array}{l}\text { Instituições de } \\
\text { Educação Superior } \\
\text { (a cada dez mil } \\
\text { habitantes) }\end{array}$ & Máx. & 3,55 & Ivatuba & Máx. & 3,32 & Ivatuba \\
\hline
\end{tabular}




\begin{tabular}{llrlrrl}
$\begin{array}{l}\text { \% de } 18 \text { anos ou } \\
\text { mais com Ensino }\end{array}$ & Máx. & 63,51 & Curitiba & Máx. & 73,96 & Curitiba \\
$\begin{array}{l}\text { Fundamental } \\
\text { Completo }\end{array}$ & Mín. & 7,83 & Doutor Ulysses & Mín. & 21,20 & Doutor Ulysses \\
$\begin{array}{l}\text { Expectativa de anos } \\
\text { de estudo }\end{array}$ & Máx. & 12,32 & $\begin{array}{l}\text { São Manoel do } \\
\text { PR }\end{array}$ & Máx. & 12,83 & Godoy Moreira \\
& Mín. & 6,11 & Marquinho & Mín. & 7,40 & Tunas do Paraná \\
\hline
\end{tabular}

Fonte: Adaptado do Banco de Dados do Ipardes; Pnud (2014).

Referente aos indicadores de Educação, conforme a Tabela 3, o município de Quatro Pontes vem se destacando com a menor Taxa de Analfabetismo do Estado do Paraná, conforme indica o Instituto Paranaense de Desenvolvimento Econômico e Social, e Ivatuba como a cidade com maior número de Instituições de Ensino Superior relacionada ao número de habitantes do município. Já o Atlas do Desenvolvimento Humano, desenvolvido pelo Programa das Nações Unidas para o Desenvolvimento, apontou o município de Curitiba com o maior percentual do Estado entre jovens e adultos com o Ensino Fundamental completo para os anos de 2000 e 2010. Quanto à expectativa de anos de estudo no Estado do Paraná, os dados do PNUD apontaram um acréscimo de 4\% na expectativa máxima de anos de estudo (12,32 para 12,83 anos) e um acréscimo de 21\% na expectativa mínima (6,11 para 7,40 anos) entre os maiores e menores índices do Estado nos anos de 2000 e 2010.

\section{Tabela 4 Parâmetros da Escala de Desempenho dos Indicadores referentes à Dimensão Comunidade/Equidade}

\begin{tabular}{|c|c|c|c|c|c|c|}
\hline $\begin{array}{l}\text { Indicadores - } \\
\text { Comunidade / }\end{array}$ & \multicolumn{3}{|c|}{ Ano 2000} & \multicolumn{3}{|c|}{ Ano 2010} \\
\hline \multirow{2}{*}{$\begin{array}{l}\text { Taxa de óbitos por } \\
\text { causas ext. (cem mil } \\
\text { habitantes) }\end{array}$} & Máx. & 254,97 & Miraselva & Máx. & 232,74 & $\begin{array}{l}\text { Iracema do } \\
\text { Oeste }\end{array}$ \\
\hline & Mín. & 0,00 & - & Mín. & 0,00 & - \\
\hline \multirow[t]{2}{*}{ Razão de sexo (\%) } & Máx. & 116,36 & $\begin{array}{l}\text { Corumbataí do } \\
\text { Sul }\end{array}$ & Máx. & 116,10 & Manfrinópolis \\
\hline & Mín. & 92,06 & Curitiba & Mín. & 91,09 & Curitiba \\
\hline
\end{tabular}




\begin{tabular}{|c|c|c|c|c|c|c|}
\hline $\begin{array}{l}\text { Proporção de } \\
\text { mulheres } \\
\text { assalariadas no } \\
\text { emprego formal }(\%)\end{array}$ & $\begin{array}{l}\text { Máx. } \\
\text { Mín. }\end{array}$ & 79,35 & Marquinho & Máx. & 61,33 & $\begin{array}{l}\text { Bom Jesus do } \\
\text { Sul } \\
\text { São Carlos do } \\
\text { Ivaí }\end{array}$ \\
\hline \multirow{2}{*}{$\begin{array}{l}\text { Taxa de pobreza } \\
(\%)\end{array}$} & Máx. & 62,52 & Doutor Ulysses & Máx. & 38,11 & Doutor Ulysses \\
\hline & Mín. & 5,39 & Maringá & Mín. & 0,84 & Pato Bragado \\
\hline
\end{tabular}

Fonte: Adaptado do Banco de Dados do Ipardes; Banco de Dados do Datasus.

Analisando os indicadores relacionados à Comunidade e Equidade, pode-se visualizar a Taxa de Óbitos por Causas Externas, ou seja, os óbitos relacionados a acidentes, homicídios e suicídios, que apresentaram uma variação de 0 (mínimo) a 0,2 (máximo) sobre a população do Estado do Paraná, ou seja, nos municípios de maior incidência, para cada grupo de cem mil pessoas, mais de duzentas entraram em óbito por causas externas, conforme indicado pelo DATASUS.

Outro indicador utilizado na pesquisa foi o Razão de Sexo (\%), e este apresentou o número de homens para cada grupo de 100 mulheres, sendo que os dados coletados junto ao IPARDES demonstraram para a cidade de Curitiba 92 homens, em 2000, e 91 homens, em 2010, para cada grupo de 100 mulheres naquele município. Já outros municípios, como é o caso de Corumbataí do Sul e Manfrinópolis, apresentaram 16 homens a mais para cada grupo de 100 mulheres. Enfim, nesse indicador considerou-se, quanto mais próximo a 100, um melhor equilíbrio entre os grupos e, portanto, mais sustentável.

Outro fato verificado foi um destaque negativo para a cidade de Doutor Ulysses, pois ficou com a maior Taxa de Pobreza do Estado do Paraná nos dois períodos analisados, conforme aponta o Instituto Paranaense de Desenvolvimento Econômico e Social. Apesar de apresentar uma grande evolução apontada pela queda de 39\% da Taxa de Pobreza do município em uma década, permaneceu em 2010 novamente com a maior taxa do Estado, mais de 38\% da população daquele município ainda dentro da faixa de pobreza.

$\mathrm{Na}$ sequência estão apresentados os parâmetros utilizados para avaliação do Sistema Ambiental, através das Dimensões Terra, Ar e Recursos: 
Tabela 5 Parâmetros da Escala de Desempenho dos Indicadores referentes à Dimensão Terra, Ar e Recursos

\begin{tabular}{|c|c|c|c|c|c|c|}
\hline $\begin{array}{l}\text { Indicadores - } \\
\text { Terra, Ar e }\end{array}$ & & & 2000 & & An & 2010 \\
\hline $\begin{array}{l}\text { Cobertura por mata } \\
\text { atlântica }\end{array}$ & Máx. & 0,00 & - & Máx. & 80,00 & $\begin{array}{l}\text { Guaraqueçaba/ } \\
\text { Guaratuba }\end{array}$ \\
\hline & Mín. & 0,00 & - & Mín. & 0,00 & - \\
\hline Razão de veículos a & Máx. & 423,26 & Curitiba & Máx. & 683,81 & Curitiba \\
\hline & Mín. & 7,72 & Guaraqueçaba & Mín. & 46,63 & Guaraqueçaba \\
\hline Despesas & Máx. & 63,26 & Boa Esperança & Máx. & 160,15 & $\begin{array}{l}\text { São José dos } \\
\text { Pinhais }\end{array}$ \\
\hline $\begin{array}{l}\text { gestão ambiental } \\
\text { (per capita) }\end{array}$ & Mín. & 0,00 & - & Mín. & 0,00 & - \\
\hline ICMS Ecológico - & Máx. & 249,88 & $\begin{array}{l}\text { Serranópolis do } \\
\text { Iguaçu }\end{array}$ & Máx. & 800,28 & Alto Paraíso \\
\hline & Mín. & 0,00 & - & Mín. & 0,00 & - \\
\hline
\end{tabular}

Fonte: Adaptado do Banco de Dados do Ipardes; Inpe (2011).

A Cobertura por Mata Atlântica Remanescente foi o indicador utilizado para avaliar a Dimensão Terra na pesquisa, sendo assim, considerou-se a proporção de área atual de Mata Atlântica para o ano pesquisado em relação à maior cobertura encontrada no Estado. Cabe salientar que, para o ano de 2000, não foram encontradas informações desmembradas por Mesorregiões para o indicador Cobertura por Mata Atlântica, apenas para o Estado do Paraná em geral, sendo esses resultados comentados mais adiante na pesquisa.

Já no ano de 2010, como limites para a composição da Escala de Desempenho, os dados pesquisados apontaram os municípios de Guaraqueçaba e Guaratuba, situados na porção Leste do Território Paranaense e na área de conservação da Serra do Mar, com a maior cobertura de Mata Atlântica do Estado, de acordo com o Instituto Nacional de Pesquisas Espaciais (INPE), estimada em 80\% de Mata Atlântica Remanescente. Sendo assim, estes municípios foram considerados nesta pesquisa como totalmente sustentáveis especificamente para este indicador. $\mathrm{E}$ como limite mínimo foi estipulado o índice de $0 \%$ (totalmente insustentáveis). 
Para avaliar a Dimensão Ar, foi utilizado o Indicador Razão de Veículos a cada mil habitantes, assim sendo, foi verificado que a frota de veículos cresceu consideravelmente no Paraná, chegando a 2 veículos para cada 3 pessoas em Curitiba no ano de 2010, de acordo com o IPARDES. Para avaliar os Recursos foram pesquisadas as Despesas Municipais com Gestão Ambiental per capita no Estado do Paraná. Apesar de uma grande parcela de municípios não registrarem as despesas com o meio ambiente no orçamento municipal, entre os que fazem, houve um aumento de 153\% no valor investido com Gestão Ambiental, destacando-se, portanto, no ano de 2000, o município de Boa Esperança e, em 2010, o município de São José dos Pinhais.

Outro indicador utilizado na pesquisa foi o ICMS Ecológico, que constitui uma importante parcela para compensar os municípios paranaenses que contenham áreas de preservação em seus territórios. Foi verificado que o repasse do ICMS Ecológico apresentou uma evolução no período analisado, representada pelo aumento de $220 \%$ no valor calculado per capita, entre os maiores valores repassados do ano de 2000 a 2010, a partir dos dados obtidos junto ao IPARDES. Destacando-se, portanto, neste indicador os municípios de Serranópolis do Iguaçu, em 2000, e Alto Paraíso, em 2010.

$\mathrm{Na}$ sequência, são apresentados os valores reais pesquisados de cada indicador para a Mesorregião Oeste do Paraná, bem como o resultado para com o cálculo de Equivalência Centesimal realizado de acordo com cada Escala de Desempenho delineada com seus respectivos limites expostos anteriormente. Consequentemente à Equivalência, todos os dados referentes aos indicadores são passíveis de comparações entre si, uma vez que foram classificados em uma Escala de Desempenho que varia de 0 a 100, tal como podem ser agrupados, sendo os valores considerados quanto mais próximos a 100 mais sustentáveis em relação do Estado do Paraná.

\section{Tabela 6 Resultados dos indicadores na Dimensão Saúde da Mesorregião Oeste do Paraná}

\begin{tabular}{|c|c|c|c|c|}
\hline \multirow[t]{2}{*}{ Indicadores - Dimensão Saúde } & \multicolumn{2}{|c|}{ Valor Real } & \multicolumn{2}{|c|}{$\begin{array}{c}\text { Equivalência } \\
\text { Centesimal }\end{array}$} \\
\hline & 2000 & 2010 & 2000 & 2010 \\
\hline $\begin{array}{l}\text { Taxa de mortalidade infantil (menores de } 1 \text { ano) (mil nascidos } \\
\text { vivos) }\end{array}$ & 25,18 & 17,29 & 73,28 & 71,76 \\
\hline Esperança de vida ao nascer (anos) & 70,66 & 74,47 & 60,24 & 56,92 \\
\hline Número de casos por HIV / AIDS (a cada dez mil habitantes) & 0,548 & 0,738 & 92,81 & 88,36 \\
\hline
\end{tabular}


Domićlios (urbanos e rurais) com acesso à rede geral de esgoto ou fossa séptica $(\%)$

Fonte: Dados da pesquisa.

O indicador Taxa de Mortalidade Infantil relaciona o número de óbitos de crianças menores de 1 ano de idade e o conjunto de 1.000 crianças nascidas vivas para o mesmo período. Como se pode observar na Tabela 6 , em que se encontra a média da Mesorregião Oeste do Paraná, por indicador, a Taxa de Mortalidade Infantil diminuiu 30\% em dez anos. Porém, apesar dessa queda significativa, observou-se uma diminuição de sustentabilidade do ano de 2000 para 2010. Esses dados revelam que, apesar da evolução no período, essa não acompanhou suficientemente a evolução das melhores taxas do Estado do Paraná, na qual são comparados os dados pesquisados. Ainda assim, a Mesorregião Oeste se classificou como Quase Sustentável nos dois períodos (73,28 em 2000 e 71,76 em 2010).

$\mathrm{Na}$ mesma linha de raciocínio, a Esperança de Vida ao Nascer também apresentou melhora considerando seu valor real, contudo, quando o dado é comparado ao cálculo de Equivalência Centesimal, apresentou um declive, ou seja, não acompanhou progresso dos maiores índices do Estado. Portanto, a média regional segundo o indicador mencionado variou entre Quase Sustentável $(60,24)$ e Intermediária $(56,92)$. Referente ao indicador Casos de HIV/AIDS, comparandose os dois períodos, verificou-se um aumento de 35\% em números de casos da doença. Assim, no cálculo de Equivalência Centesimal, apresentou uma pequena queda em relação à sustentabilidade da área para esse indicador, ainda assim classificando-se como Sustentável nos dois períodos (92,81 em 2000 e 88,36 em 2010).

Já o indicador Domićlios com Rede de Esgoto, refere-se ao percentual de domicílios, tanto urbanos como rurais, atendidos com Rede Geral de Esgoto ou Fossa Séptica em relação ao número total de domicílios. Verificando a Tabela 6, observamos que houve um aumento de $12 \%$ para $19 \%$ de domićlios da Mesorregião atendidos por rede de esgoto ou fossa séptica, apresentando também uma relativa melhora e consequente aumento da Sustentabilidade para o indicador, apesar de a região estudada ser considerada deficitária neste âmbito, classificandose como Insustentável (13,18 no ano de 2000 e 20,05 em 2010).

Sendo o tratamento de esgoto uma incumbência do governo, esses resultados demonstram a falta de investimentos pelo setor público na construção de redes de tratamento. Investimentos esses que podem trazer vantagens amplas em saúde e meio ambiente, uma vez que são evitados gastos públicos no combate a doenças transmitidas através da água e também na descontaminação de áreas atingidas por efluentes não tratados. 


\section{Tabela 7 Resultados dos indicadores na Dimensão Econômica da Mesorregião Oeste do Paraná}

\begin{tabular}{lccccc}
\hline \multicolumn{1}{c}{ Indicadores - Dimensão Econômica } & \multicolumn{2}{c}{ Valor Real } & \multicolumn{3}{c}{$\begin{array}{c}\text { Equivalência } \\
\text { Centesimal }\end{array}$} \\
& 2000 & 2010 & 2000 & 2010 \\
Índice de Desenvolvimento Humano (IDH-M) & 0,622 & 0,717 & 65,28 & 62,00 \\
Índice de Gini - Geral & 0,55 & 0,47 & 49,65 & 56,24 \\
Produto Interno Bruto per capita (R \$1,00) & $7.559,00$ & $16.795,00$ & 13,70 & 11,16 \\
Renda média domiciliar per capita (R\$1,00) & 449,28 & 679,76 & 27,48 & 32,14 \\
\hline
\end{tabular}

Fonte: Dados da pesquisa.

O Índice de Desenvolvimento Humano é um dos indicadores mais importantes do contexto internacional ao local, por isso não se poderia deixar de constar nessa pesquisa. O IDH-M representa o desenvolvimento dos municípios, sendo considerado, quanto mais próximo a 1, mais desenvolvido. Na Mesorregião Oeste do Paraná observamos um bom resultado para este indicador e uma importante evolução no período analisado. Contudo, observando-se a Equivalência Centesimal, a média regional não conseguiu acompanhar o mesmo desempenho do Estado do Paraná, apresentando, desta forma, um pequeno decréscimo no período analisado, passando de 65,28 para 62,00, porém, classificando-se ainda como Quase Sustentável.

Quanto ao Índice de Gini, que corresponde, de acordo com o Instituto Brasileiro de Geografia e Estatística, à medida do grau de concentração de uma distribuição, comumente utilizada para análise da distribuição de renda, cujo valor varia de zero, o que nesse caso considera-se perfeita igualdade, até um, que se refere à desigualdade máxima (IBGE, 2012), o resultado pesquisado demonstrou que a renda está sendo mais bem distribuída em 2010 na Mesorregião, elevando as taxas de sustentabilidade para esse indicador de 49,65 no ano de 2000 para 56,24 em 2010 .

No tocante aos outros dois indicadores utilizados para avaliação da Dimensão Econômica, o PIB per capita e a Renda Média Domiciliar per capita, estes também apresentaram um aumento significativo em dez anos. Entretanto, não acompanharam o mesmo desempenho do Estado do Paraná. Isso porque o município de Araucária, região metropolitana de Curitiba, apresentou um elevado índice per capita, tendo grande efeito no cálculo de Equivalência Centesimal para a Mesorregião Oeste. E quanto à Renda Média Domiciliar per capita, esta teve grande consequência ao município de Curitiba, capital do Estado, que apresentou 
disparadamente o maior índice do Estado. Logo, a média regional permaneceu como Quase Insustentável, sendo 27,48 no ano de 2000 e 32,14 em 2010.

\section{Tabela 8 Resultados dos indicadores na Dimensão Educação da Mesorregião Oeste do Paraná}

\begin{tabular}{|c|c|c|c|c|}
\hline \multirow{2}{*}{ Indicadores - Dimensão Educação } & \multicolumn{2}{|c|}{ Valor Real } & \multicolumn{2}{|c|}{$\begin{array}{c}\text { Equivalência } \\
\text { Centesimal }\end{array}$} \\
\hline & 2000 & 2010 & 2000 & 2010 \\
\hline Taxa de analfabetismo de 15 anos ou mais (\%) & 12,70 & 8,92 & 61,31 & 58,01 \\
\hline Instituições de Educação Superior (cada dez mil habitantes) & 0,054 & 0,081 & 1,48 & 2,38 \\
\hline$\%$ de 18 anos ou mais com ensino fundamental completo & 32,53 & 45,15 & 44,36 & 45,39 \\
\hline Expectativa de anos de estudo & 10,41 & 10,81 & 69,19 & 62,85 \\
\hline
\end{tabular}

Fonte: Dados da pesquisa.

Analisando a região segundo a Taxa de Analfabetismo, verifica-se que a área apresentou avanços quando comparada aos valores reais do ano de 2000 e 2010, contudo, quando colocada perante a Escala de Desempenho relacionada ao Estado do Paraná, o resultado foi uma diminuição no desempenho, passando de 61,31 para 58,01 em 2010, fazendo com que a média regional permanecesse na linha imaginária entre a classificação Intermediária e Quase Sustentável (próximo a $60)$.

Outro índice utilizado para avaliar a Dimensão Educação foi o número de Instituições de Ensino Superior, notou-se que este número permaneceu muito baixo na Mesorregião Oeste do Paraná, fazendo com que muitas pessoas migrem para outras regiões do Estado ou do País em busca de qualificação profissional. Sendo, portanto, essa variável caracterizada como Insustentável. Quanto ao percentual da população com 18 anos ou mais com Ensino Fundamental Completo, o que se visualizou foi que a região em estudo encontra-se em uma posição Intermediária, na classificação por sustentabilidade, quando comparada ao Estado como um todo. E, além disso, houve pouca variação positiva em 10 anos. Sendo, portanto, um objetivo ainda a ser alcançado para muitos municípios da região. No que se refere à Expectativa de Anos de Estudo, ou seja, de quanto tempo espera-se que a criança permaneça na escola, os resultados apresentaram a classificação Quase Sustentável para esse indicador, apesar de apresentar um pequeno decréscimo na Escala de Desempenho. 


\section{Tabela 9 Resultados dos indicadores na Dimensão Comunidade/Equidade da Mesorregião Oeste do Paraná}

\begin{tabular}{lccccc}
\hline \multicolumn{1}{c}{ Indicadores - Dimensão Comunidade/Equidade } & \multicolumn{2}{c}{ Valor Real } & \multicolumn{2}{c}{$\begin{array}{c}\text { Equivalência } \\
\text { Centesimal }\end{array}$} \\
& 2000 & 2010 & 2000 & 2010 \\
Taxa de Óbitos por Causas Externas (cem mil habitantes) & 66,92 & 104,41 & 73,75 & 55,14 \\
Razão de Sexo (\%) & 102,17 & 99,63 & 71,53 & 73,98 \\
Proporção de Mulheres Assalariadas no Emprego Formal (\%) & 41,24 & 45,04 & 37,28 & 59,29 \\
Taxa de Pobreza (\%) & 26,92 & 8,62 & 62,31 & 79,13 \\
\hline
\end{tabular}

Fonte: Dados da pesquisa.

Relativo à Dimensão Comunidade considerou-se, no indicador Taxa de Óbitos por Causas Externas, a intensidade da força de morrer um indivíduo por 100 mil habitantes, por causas externas (acidentes de trânsito, homicídios e suicídios). Ficou evidente, pelos números apresentados, que a mortalidade por causas externas aumentou em dez anos na área em estudo, diminuindo o nível de sustentabilidade para esse indicador em 25\%, passando de Quase Sustentável para Intermediária $(73,75$ para 55,14).

Avaliando a Dimensão Equidade temos como um dos indicadores a Razão de Sexo (\%), a qual expressa a relação quantitativa entre os sexos, ou seja, o número de homens para cada grupo de 100 mulheres em determinado espaço geográfico no ano considerado. Percebeu-se, pela pesquisa, que houve um pequeno desequilíbrio entre o número de homens e mulheres na região analisada, colocando-se na faixa denominada de Quase Sustentável na avaliação da sustentabilidade para esse indicador.

Outro indicador de relevância para compor a Dimensão Equidade é o Percentual de Mulheres Assalariadas no Emprego Formal. De acordo com esse indicador a Mesorregião Oeste apresentou um aumento no número de Mulheres Assalariadas no Emprego Formal, representando, assim, uma diminuição na informalidade e um maior acesso a direitos previdenciários (INSS), como também direito ao Fundo de Garantia por Tempo de Serviço (FGTS). Logo, a Mesorregião avançou, passando de um quadro Quase Insustentável para classificação Intermediária (37,28 em 2000 para 59,29 em 2010).

No tocante ao indicador Taxa de Pobreza, a Mesorregião Oeste demonstrou bons índices quando comparada ao Estado, apresentando uma diminuição significativa na Taxa de Pobreza do ano de 2000 para 2010. Avaliando a média geral da Mesorregião Oeste do Estado do Paraná, esta obteve grandes avanços, 
classificando-se como Quase Sustentável (62,31 em 2000 e 79,13 em 2010). Na sequência, são apresentados os resultados perante o Sistema Ambiental:

\section{Tabela 10 Resultados dos indicadores para o Sistema Ambiental da Mesorregião Oeste do Paraná}

\begin{tabular}{lccccc}
\hline \multicolumn{1}{c}{ Indicadores - Dimensão Terra, Ar e Recursos } & \multicolumn{2}{c}{ Valor Real } & \multicolumn{2}{c}{$\begin{array}{c}\text { Equivalência } \\
\text { Centesimal }\end{array}$} \\
Cobertura por mata atlântica remanescente (\%) & 2000 & 2010 & 2000 & 2010 \\
Razão de veículos (cada mil habitantes) & - & 10,16 & - & 12,70 \\
Despesas municipais com gestão ambiental (per capita) & 205,25 & 444,71 & 52,46 & 37,53 \\
ICMS Ecológico - (R\$1,00) (per capita) & 5,99 & 21,13 & 9,28 & 12,93 \\
\hline
\end{tabular}

Fonte: Dados da pesquisa.

Conforme observado na Tabela 10, não foram encontrados dados desmembrados por Mesorregião para o indicador Cobertura por Mata Atlântica Remanescente para o ano de 2000, somente dados agregados para o Estado do Paraná. De acordo com o Relatório dos Remanescentes Florestais da Mata Attântica, período de 1995-2000, o Estado do Paraná possuía no ano de 2000 cerca de 20,33\% da Mata Atlântica original do Estado, correspondente a 3.920.628 hectares (INPE, 2003). Já no ano de 2010, esse percentual se reduziu expressamente pela metade, restando apenas 1.960.644 hectares de Mata Atlântica no Estado, ou seja, 9,97\% de remanescentes florestais (INPE, 2011).

Já no ano de 2010 o que encontrou-se na Mesorregião Oeste foi a cobertura por Mata Atlântica Remanescente de 10,16\% apenas, apresentando um resultado de 12,70 perante a Escala de Desempenho, classificando-se a região como Insustentável para este indicador. Seguindo com a avaliação do Sistema Ambiental, outro indicador utilizado foi a Razão de Veículos a cada mil habitantes, que teve como objetivo principal relacioná-la à qualidade do ar da região pesquisada. Em dez anos, percebeu-se que a frota de veículos cresceu em disparidade, diminuindo o nível de sustentabilidade de 52,46 no ano de 2000 para 37,53 em 2010. Partindo da classificação Intermediária para Quase Insustentável.

Por outro lado, cresceram as Despesas Municipais com Gestão Ambiental, demonstrando que a Mesorregião está investindo na preservação dos recursos naturais, ainda que pouco. Da mesma forma aconteceu com o repasse de ICMS Ecológico, os valores demonstraram que ainda são poucas as reservas de recursos 
naturais cadastradas no programa. Classificando esses dois últimos indicadores como Insustentáveis para a Mesorregião Oeste do Paraná.

Por fim, a partir das médias aritméticas das dimensões, chegou-se aos resultados da avaliação do Bem-Estar do Sistema Humano para a Mesorregião Oeste do Estado do Paraná, que demonstraram uma classificação Intermediária (entre Sustentável e Insustentável) para 2000 e 2010 (51,05 e 52,18). Em contrapartida, percebeu-se que a situação encontrada em relação ao Bem-Estar do Sistema Ambiental é preocupante, além da classificação Quase Insustentável $(22,31)$ apresentada no ano de 2000, e, passados dez anos, em 2010, os dados apresentados apontaram que a degradação do meio natural não cessou. Com o aumento do desmatamento, aumento da frota de veículos, poucos investimentos em Gestão Ambiental e reservas ambientais, a área de estudo classificou-se como Insustentável $(16,80)$.

O Barômetro da Sustentabilidade apresentado (Figura 3) reflete o método sugerido por Prescott-Allen (2001) e discutido nessa pesquisa. Nele encontram-se esferas verticais e horizontais ilustrando a localização dos índices para as Dimensões do Sistema Humano e do Sistema Ambiental, respectivamente. A localização do estágio do Desenvolvimento Sustentável da Mesorregião Oeste do Estado do Paraná é determinada pela intersecção de duas retas imaginárias traçadas, conforme o desempenho dos dois sistemas (Figura 4).

Figura 4 Barômetro da Sustentabilidade da Mesorregião Oeste do Paraná, 2000 e 2010

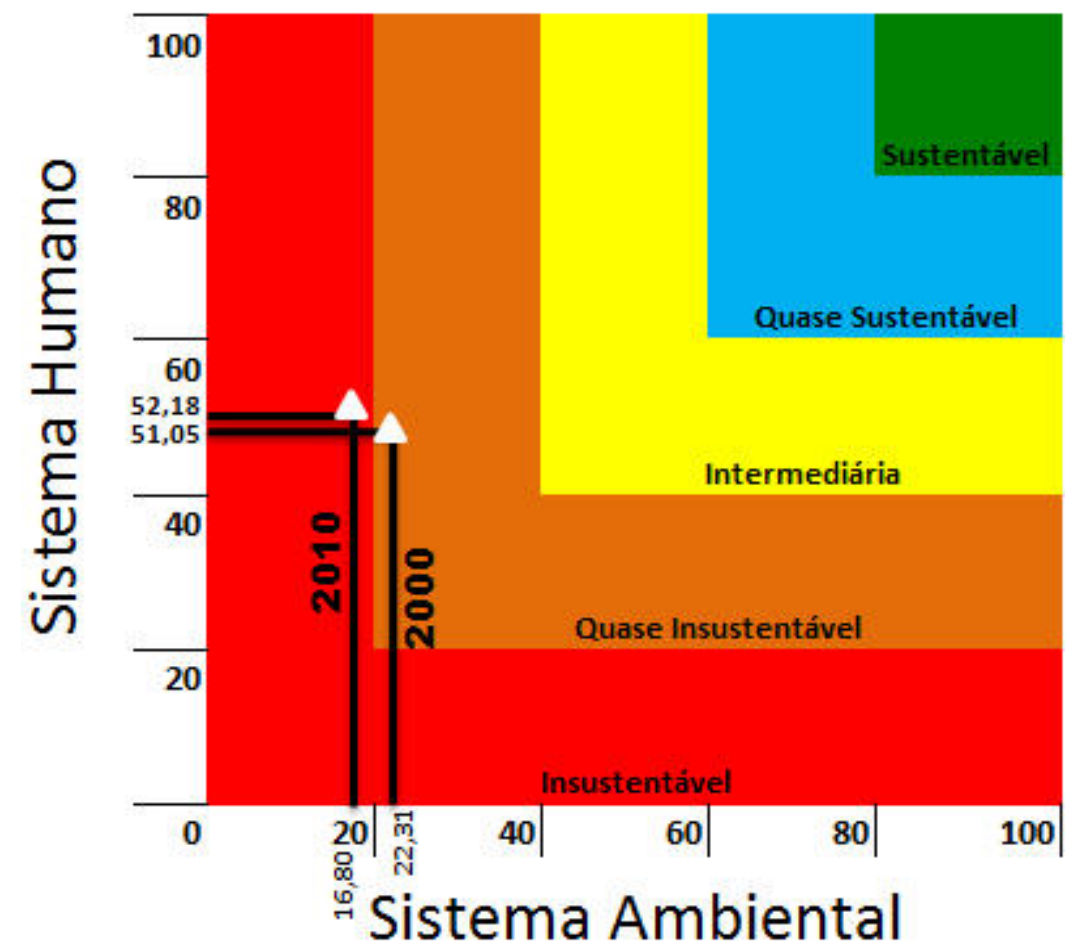

Fonte: dados da pesquisa. 
De acordo com os dados apurados nesse estudo, para o ano 2000, a intersecção das duas retas apontou o estágio Quase Insustentável. E em 2010 houve um pequeno aumento no desempenho do Sistema Humano, entretanto um recuo no desempenho do Sistema Ambiental, classificando a Mesorregião Oeste do Paraná como Insustentável. Esses resultados procedem de que a avaliação do Desenvolvimento Sustentável da Mesorregião Oeste do Paraná apontou graves problemas em diferentes indicadores, principalmente nos ambientais. Além da devastação da Mata Atlântica Nativa apontada na pesquisa, gerando danos ao meio natural, o que se produziu são produtos de baixo valor agregado, representados pelas commodities agrícolas, e traduzindo-se em um reduzido valor do Produto Interno Bruto regional, quando comparado ao Estado do Paraná.

Além disso, apurou-se o baixo percentual de atendimento com Rede de Esgotos ou Fossa Séptica nos municípios, o que se traduz em alto risco de contaminação dos lençóis freáticos e transmissão de doenças à população. Também verificou-se que há poucas instituições de Ensino Superior se comparado à demanda pelo número de habitantes, considerando que a graduação em Ensino Superior pode representar importantes avanços em termos de emprego e renda, entende-se que estimular a maior escolaridade e aprimorar a qualidade do ensino pode ter repercussões diretas na economia da região.

Ademais, constataram-se na pesquisa que são poucos os investimentos realizados pelos municípios em Gestão Ambiental e consequentemente é limitada a captação de fundos para investimentos com a preservação e recuperação dos recursos naturais, como o recebimento do ICMS Ecológico.

\section{Considerações finais}

Como se percebe, as discussões sobre o Desenvolvimento Sustentável vêm sendo fomentadas nas últimas décadas em quase todas as esferas da sociedade. Entretanto, mais do que discussões, tornam-se necessárias práticas a partir de uma tomada de consciência da população, responsável pela preservação do meio ambiente e dos recursos naturais em prol de sua própria qualidade de vida, bem como de seus descendentes.

Embora se reconheça que a sociedade está cada vez mais consumista, visto que as facilidades advindas dos recursos tecnológicos, hoje existentes, tornaram-se necessidades, não há evidências de que tal modo de vida se modifique. Todavia, se esse cenário continuar sendo o caminho a ser perseguido, há comprovações, tanto por indicadores ambientais quanto humanos, que essa escolha tende a levar a um estágio ainda maior de degradação das condições de vida.

Nesse sentido, o presente estudo fez uso de informações que permitissem analisar o Desenvolvimento Sustentável da Mesorregião Oeste do Paraná em comparação 
com o restante do Estado, para os anos de 2000 e 2010, avaliando o Bem-Estar do Sistema Humano e o Bem-Estar do Sistema Ambiental da região através do Barômetro da Sustentabilidade. De forma que em relação ao Sistema Humano pode-se concluir que na Mesorregião Oeste do Estado do Paraná houve progressos, principalmente relacionados ao crescimento da Renda Média Domiciliar per capita, pertinente ao aumento de Mulheres Assalariadas no Emprego Formal da região, gerando importante redução da Taxa de Pobreza da população e melhor distribuição de renda, fato apontado pelo Índice de Gini, além de aumento nos investimentos em Rede de Esgotos, ainda que reduzido.

Em contrapartida, os demais indicadores referentes ao Sistema Humano não demonstraram melhora de comportamento perante a Escala de Desempenho, ou que não foi suficiente para acompanhar o desempenho desses indicadores no Estado do Paraná. Por esses motivos, os resultados para a Sustentabilidade do Sistema Humano na Mesorregião foram de 51,05 em 2000 e de 52,18 em 2010, classificando a Mesorregião na faixa Intermediária (40 a 60), em uma escala que varia de 0 a 100 perante o Barômetro da Sustentabilidade.

Com relação ao Sistema Ambiental, a situação encontrada foi considerada preocupante em relação ao Bem-Estar do Ecossistema e à Sustentabilidade da Mesorregião Oeste do Estado do Paraná. Pois, além de os resultados apresentados no ano de 2000 não serem atraentes, ainda pioraram em 2010. Obviamente uma bruta contraposição ao processo e de certa forma até um retrocesso, pois melhoraram os indicadores humanos e pioraram os indicadores ambientais.

Cerca de três décadas depois de um documento histórico alertar para a situação do planeta (The Limits to Growth), o que aconteceu foi à continuação de uma elevada degradação. Cerca de 50\% da Cobertura por Mata Atlântica Remanescente que restou no ano de 2000 ainda foi devastada até 2010 no Estado do Paraná. Diante do exposto, a Sustentabilidade do Sistema Ambiental da Mesorregião Oeste do Paraná apresentou o resultado de 22,31 para o ano de 2000 e de 16,80 para o ano de 2010, classificando-se inicialmente como Quase Insustentável e, mais recentemente, como Insustentável.

Tais acontecimentos podem estar relacionados ao forte desmatamento que ocorreu na Mesorregião em seu período de colonização e a agricultura intensiva ali instalada, o que ocasionou diversos impactos ambientais, principalmente sobre os solos e as águas. Além disso, os dados analisados comprovaram a carência no desenvolvimento de projetos ambientais e a deficiência na criação de novas reservas ambientais para captação de recursos provenientes do Estado como o ICMS Ecológico. 


\section{Referências}

AGENDA 21. United National Conference on Environmental and Development. Rio de Janeiro, 1992.

BOFF, Leonardo. Sustentabilidade: o que é - o que não é. Rio de Janeiro: Vozes, 2012.

BONCHRISTIANI, Caetano Carlos; KUHN, Sérgio Luiz; SHIKIDA, Pery Francisco Assis. Desenvolvimento Agrícola Sustentável: Principais Passivos Ambientais da Região Oeste do Paraná. REUNA, vol. 10, n. 2, p. 41-56, mai./ago., 2005.

BUARQUE, Sérgio C. Desenvolvimento Sustentável da Zona da Mata de Pernambuco. SEPLAN/PR-IICA, (Versão final, mimeo.), Recife, mar. 1994.

HOGAN, D. J. Dinâmica populacional e mudança ambiental: cenários para o desenvolvimento brasileiro. Campinas: Núcleo de Estudos de PopulaçãoNepo/Unicamp, 2007.

IBGE, Instituto Brasileiro de Geografia e Estatística. Indicadores de Desenvolvimento Sustentável: Brasil 2012. Estudos e Pesquisas. Informação Geográfica, n. 9. Rio de Janeiro, 2012.

IPARDES. Instituto Paranaense de Desenvolvimento Econômico e Social. Base de dados do Estado - BDEweb. Disponível em: http://www.ipardes.pr.gov.br/ imp/index.php. Acesso em: 14 abr. 2014.

- Instituto Paranaense de Desenvolvimento Econômico e Social. Indicadores de Desenvolvimento Sustentável: por bacias hidrográficas do Estado do Paraná. Curitiba: 2013. 245 p. Disponível em: http://www.ipardes.gov.br/biblioteca/docs /indicadores 2013.pdf. Acesso em: 18 set. 2014.

- Instituto Paranaense de Desenvolvimento Econômico e Social. Oeste paranaense: o 3. espaço relevante: especificidades e diversidades. Curitiba: IPARDES, 2008. 86 p. (Estudo Os Vários Paranás)

INPE. Instituto Nacional de Pesquisas Espaciais. Atlas dos remanescentes florestais da Mata Atlântica: período 2008-2010. 2011. Disponível em: http://www.inpe.br/noticias/arquivos/pdf/atlasrelatoriofinal.pdf. Acesso em: 2 nov. 2014. 
Instituto Nacional de Pesquisas Espaciais. Atlas dos remanescentes florestais da Mata Atlântica: período 1995-2000. 2003. Disponível em: http://mtc-m12.sid.inpe.br/col/sid.inpe.br/jeferson/2003/06.02.07.45/doc/ R elatorio Atlas.pdf. Acesso em: 2 nov. 2014.

KRAMA, M. R. Análise dos indicadores de desenvolvimento sustentável no Brasil, usando a ferramenta Painel de Sustentabilidade. 185 p. 2009. Dissertação (Mestrado em Engenharia de Produção e Sistemas) Pontifícia Universidade Católica, Curitiba, 2009.

LEAL, Carmem Terezinha; PEIXE, Blênio César Severo. Estudo dos indicadores de sustentabilidade ambiental no Paraná com recorte para os recursos hídricos utilizando o geoprocessamento. In: PEIXE, Blênio César Severo et al. (Orgs.). Formulação e gestão de políticas públicas no Paraná: reflexões, experiências e contribuições. vol. 2. 820p. Imprensa Universitária da Universidade Federal do Paraná, 2010.

LOUETTE, Anne. Indicadores de nações: uma contribuição ao diálogo da sustentabilidade. 1. ed. São Paulo: WHH - Willis Harman House, 2009.

LUCENA, André Duarte; CAVALCANTE, Jaqueline Nunes; CÂNDIDO, Gesinaldo Ataíde. Sustentabilidade do Município de João Pessoa: uma aplicação do barômetro da sustentabilidade. Revista Brasileira de Gestão e Desenvolvimento Regional - G\&DR, Taubaté, SP, Brasil, v. 7, n. 1, p. 19-49, jan./abr., 2011.

MELLO, L. F. de. Orçamento participativo e agenda 21 local: uma proposta ambiental estratégica para Campinas, SP. 2003. Dissertação (Mestrado em Engenharia Civil) Faculdade de Engenharia Civil, Arquitetura e Urbanismo, Universidade Estadual de Campinas, 2003.

OLIVEIRA, Gilson Batista de. Uma discussão sobre o conceito de desenvolvimento. Revista da FAE, Curitiba, v. 5, n. 2, p. 37-48, mai./ago., 2002.

PNUD, Programa das Nações Unidas para o Desenvolvimento. Desenvolvimento Humano e IDH. Disponível em: http://www.pnud.org.br/IDH/DH.aspx. Acesso em: 15 abr. 2014.

PRESCOTT-ALLEN, R. The Wellbeing of Nations: a country-by-country index of quality of life and the environment. Washington, DC: Island Press, 2001. 
PRESTES, Marcia Ferreira. Indicadores de Sustentabilidade em urbanização sobre áreas de mananciais: uma aplicação do barômetro da sustentabilidade na ocupação do Guarituba - município de Piraquara - Paraná. 191 p. 2010. Dissertação (Mestrado em Construção Civil) Universidade Federal do Paraná, Curitiba. 2010.

RIPPEL, R. Migração e desenvolvimento econômico no Oeste do Estado do Paraná: uma análise de 1950 a 2000. 2005. Tese (Doutorado em Demografia) Instituto de Filosofia e Ciências Humanas, Universidade Estadual de Campinas, 2005.

Fronteiras em movimento - transformações demográficas numa região emblemática: o oeste paranaense de 1970 a 2010. In: VIII Encontro Nacional sobre Migrações, GT Migração - ABEP - Associação Brasileira de Estudos Populacionais, Belo Horizonte/MG, 23-25 de outubro de 2013. Anais... Belo Horizonte/MG: ABEP, vol. 1, p. 82-100, 2013.

ROMEIRO, Ademar Ribeiro; REYDON, Bastiaan Philip; LEONARDI, Maria Lucia Azevedo (Orgs.). Economia do meio ambiente: teoria, políticas e a gestão de espaços regionais. Campinas, SP: UNICAMP/IE, 1999.

SIENA, Osmar. Método para avaliar progresso em direção ao desenvolvimento sustentável. 234p. 2002. Tese (Doutorado em Engenharia de Produção) Programa de Pós-Graduação em Engenharia de Produção, Universidade Federal de Santa Catarina, Florianópolis, UFSC, 2002.

VAN BELLEN, H. M. Indicadores de sustentabilidade: uma analise comparativa. 2002. Tese (Doutorado em engenharia de produção) Programa de Pós-Graduação em Engenharia de Produção, Florianópolis, UFSC, 2002.

WOEHL, Oraide Maria. Desenvolvimento Sustentável. 1 ed. Curitiba: Editora Organic Trading, 2008.

Endereço para correspondência:

Flavia Hachmann - flaviahachmann@hotmail.com

Rua D. Pedro, 1151, Centro

85.960-000 Marechal Cândido Randon/PR, Brasil

Ricardo Rippel-ricardorippel@yahoo.com.br

Rua da Faculdade, 645, Jardim Santa Maria

85.903-000 Toledo/PR, Brasil 